Many global-workspace theorists don't see it this way, and Dennett says they are "surrendering just when victory is at hand". The critical point hinges on what he calls the 'hard question': "And then what happens?". (This is not to be confused with Chalmers' 'hard problem', which Dennett thinks is illusory.) If you think that something has to happen next, such as entering consciousness or becoming conscious, then you are still wallowing in mystery.

But if the devil had stuck with his original multiple-drafts theory, he would surely have gone further. One of its most startling claims,

\section{Making progress?}

FAB: The Coming Revolution on Your Desktop - From Personal Computers to Personal Fabrication by Neil Gershenfeld

Basic Books: 2005. 288 pp. \$26, £19.99

\section{Don Ihde}

What happens to the notion of 'revolution' when it occurs every day, month or year? I suspect it comes to mean the same as 'normal' - or it becomes irritating, as constant changes end up preventing planned action.

The rhetorical cast of $F A B$ is one of technofantasy and wild projection, which strangely recalls some equally extravagant medieval theological puzzles. "Can God create a stone that is too heavy for him to lift?" is paralleled here by another puzzle: can we humans build a machine that could then make a machine better than itself? This technofantasy opens $F A B$, which stands for personal fabrication: a programmable personal fabricator will be able "to make anything, including itself, by assembling its atoms. It will be a self-reproducing machine."

But, at least the author, Neil Gershenfeld - former director of the Media Lab at Massachusetts Institute of Technology (MIT) and now director of its Center for Bits and Atoms - recognizes this as a "long-standing science-fiction staple". Boundless enthusiasm and boys-and-toys utopianism seem to be the tradition, and I had a hard time overcoming my own scepticism in order to get to a more sober assessment of what is happening.

The book arose from a popular course at MIT, "How To Make (Almost) Anything", taught by Gershenfeld. It draws many students from diverse backgrounds, all enthusiastic to build, or 'personally fabricate', things. From the second chapter on, we get descriptions of some of these objects. ScreamBody is a sort of fuzzy soundproofed knapsack into which the user screams, but passers-by cannot hear; it contains a recording device that can then later be played and, with the bag open, be heard by others. Another is a web browser designed for use by parrots, made by Dennett in Consciousness Explained (Little, Brown, 1991), is that "there are no fixed facts about consciousness independent of particular probes". I took this to mean something like this: at any time there are multiple versions of representations in the brain, none of which is conscious or unconscious. Only when the system is probed - for example by asking a question or requiring an action - does one of the drafts have consequences that cause us to say, after the fact, that it was conscious. In other words, there are no conscious and unconscious streams; nothing ever 'enters consciousness'; there

who seem to like their new toy. Yet another is an alarm clock that you have to wrestle with to turn off, stopping you slipping back to sleep. These are indeed imaginative fabrications.

It seems that the heart of this operation is a network of new hook-ups, connecting different tools and processors to programmed computer assistance: computer-assisted design, computer-assisted manufacture, computer-assisted cutting... If you imagine a desktop computer that is hooked up not to a two-dimensional printer but to a threedimensional product producer, you've got the idea.

The trajectory that dominates FAB is the production of many types of 'Hello World' artefacts. Hello World, the standard test for computer languages, can be printed out by any desktop computer hooked up to a printer, but when hooked up to engraving devices it can be printed as a bas-relief, cut out as independent letters (hooked up to a laser cutter) or even in heavy material (using a supersonic water cutter).

But you could use the same water cutter to produce polycarbonate plastic bicycle frames of any design, as they do on the MIT course. The other bicycle parts are off the shelf, and when assembled the various designs could then be seen on the streets of Cambridge. I can see why this class is fun, and as a bricolage inventor myself from my Kansas childhood - my brother and I welded together a bale loader from our father's junk pile - I can begin to catch the infectious enthusiasm that permeates FAB. Yet I can't shake the doubts: what is the revolutionary future of using a US\$100,000 water cutter to make polycarbonate bicycle frames? At $\$ 20,000$ for Fab Labs exported to the Third World, the process seems rather expensive.

What is infectious, and possibly of some revolutionary importance, is the way in which Fab Labs have been exported and prepared for use by children and distant, Third World is no "crucial finish line or boundary somewhere in the brain, marking a place where the order of arrival equals the order of 'presentation' in experience".

Yet the global-workspace theorists believe in conscious and unconscious streams, in contents becoming conscious, and in looking for the neural correlates of the 'movie in the brain'. I think they still need the old devil.

Susan Blackmore is a freelance writer, lecturer and broadcaster, and a visiting lecturer at the University of the West of England, Bristol, UK.
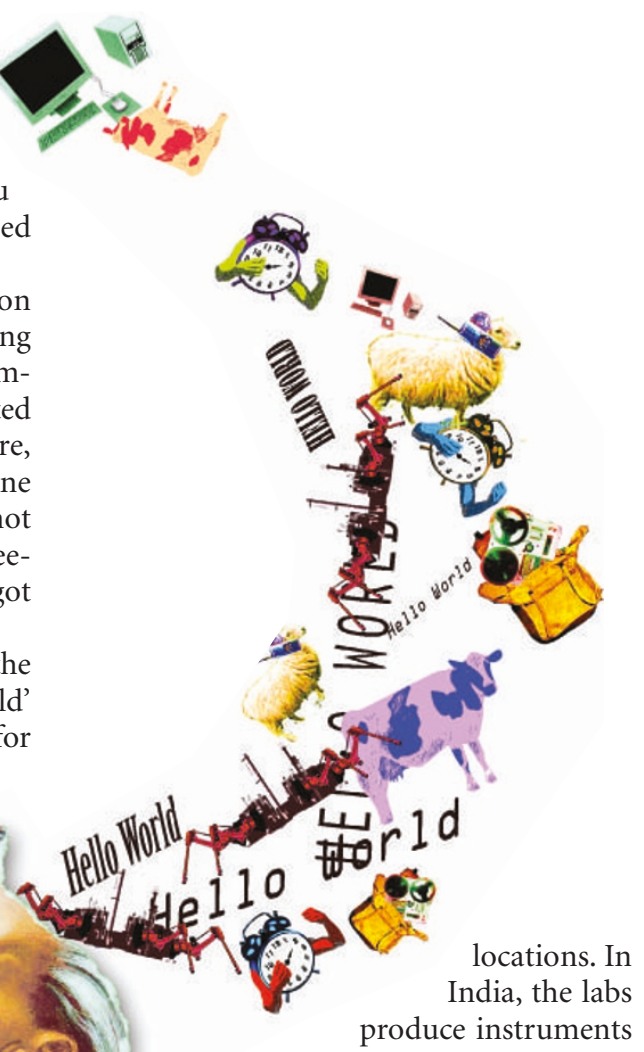

that can measure fat and milk/cream ratios in milk, which villagers can then use to good effect. In Norway, transmitters have been developed to help herders locate their sheep, and they have been transformed into local networks for communication as well. Children from a slum learned to program their own lab, on a computer placed in a hole in the wall, often with innovations never dreamed of by the designers.

It strikes me that the 'revolution' that emerges is that of self-learned skills through playing with Fab Labs. Desktops hooked up to various new connections, flexible enough for eight-year-olds to invent things, in effect democratize this technical development. Such technological multistability, of course, remains unpredictable. And so much often begins in play. That is the possibility created by Fab Labs. "Imagination au pouvoir" was, after all, the slogan of the revolutionary Days of May in 1968 Paris.

Don Ihde is in the Department of Philosophy,

Stony Brook University, New York 11794, USA. 